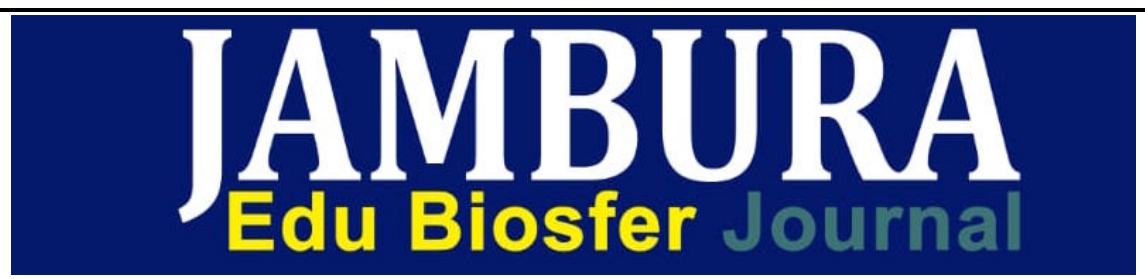

Journal homepage: http://ejurnal.ung.ac.id/index.php/edubiosfer

\title{
PENDATAAN JENIS BUAH LOKAL INDONESIA KOLEKSI KEBUN RAYA PURWODADI
}

\author{
Melisnawati H. Angio ${ }^{a}$, Rony Irawanto \\ ${ }^{a}$ Balai Konservasi Tumbuhan Kebun Raya Purwodadi_LIPI, Jl. Raya Surabaya - Malang No.KM. 65, Pasuruan 67163, \\ Indonesia.Email:melisnawati09@gmail..com
}

\begin{abstract}
Buah lokal Indonesia adalah jenis buah-buahan lokal yang tumbuh secara alami dan yang berasal dari kawasan Indonesia Tujuan penelitian ini untuk mengetahui keanekaragaman jenis tanaman buah lokal Indonesia yang dapat dikonsumsi manusia (edible fruit) sehingga dapat menjadi dasar pengelolaan dan pengambilan kebijakan terkait pembuatan rute tracking dan taman tematik buah lokal Kebun Raya Purwodadi. Pengumpulan data menggunakan metode observasi langsung di lapangan, sedangkan pemanfaatan serta potensi jenis tanaman berdasarkan wawancara dan studi literatur. Berdasarkan hasil pengamatan, terdapat 95 jenis tanaman buah lokal yang termasuk dalam 24 famili.
\end{abstract}

Keywords: Buah lokal Indonesia, Kebun Raya Purwodadi

\section{Pendahuluan}

Indonesia merupakan negara dengan keanekaragaman jenis tertinggi di dunia karena terletak di daerah katulistiwa yang mempunyai tipe hutan hujan tropik cukup unik Kekayaan jenis tumbuhan di hutan Indonesia sampai sekarang belum didapat angka yang pasti. Sampai sekarang paling tidak terdapat 30.000 jenis tumbuhan berbunga yang sebagian besar masih tumbuh liar di hutan-hutan di berbagai kawasan di Indonesia. Saat ini baru sekitar 4.000 jenis saja yang diketahui telah dimanfaatkan langsung oleh penduduk dan hanya sekitar seperempatnya yang telah dibudidayakan bahkan mungkin kurang dari 10 persennya (Dodo, 2007). Dengan demikian masih banyak jenis-jenis tumbuhan yang belum diketahui, khususnya kelompok tanaman buah lokal Indonesia yang semakin jarang ditemui.

Buah lokal Indonesia adalah jenis buah-buahan lokal yang tumbuh secara alami dan yang berasal dari kawasan Indonesia (Uji, 2007). Dalam tulisan ini batasan untuk jenis buah adalah buah-buahan dari tumbuhan tahunan yang dapat dimakan (edible fruit) baik berupa buah masak ataupun masih mentah (Prosea, 1991). Jurnal Pusat Konservasi Tumbuhan Kebun Raya-LIPI menyebutkan bahwa ada 226 jenis tumbuhan buah-buahan asli Indonesia dapat dimakan yang sebagian besar tumbuh liar di hutan (184 jenis), hanya sebagian kecil yang telah dibudidayakan (62 jenis) dan 18 jenis diantaranya merupakan jenis endemik (Dodo, 2015).

Kekayaan keanekaragaman jenis dan sumber plasma nutfah buah-buahan asli Indonesia yang melimpah sampai sekarang belum dimanfaatkan secara optimal. Hal ini dapat dilihat antara lain dengan banyaknya buah-buahan import yang beredar diberbagai kota di Indonesia. Oleh karena itu kekayaan sumber daya hayati yang melimpah di Indonesia ini perlu didayagunakan semaksimal mungkin untuk memenuhi kebutuhan pangan khususnya buah-buahan.Tercatat paling sedikit ada 4 marga dari 4 suku buah-buahan asli Indonesia yang bernilai ekonomi cukup tinggi dan juga mempunyai keanekaragaman jenis yang tinggi. Masing-masing adalah suku Anacardiaceae (marga Mangifera), Clusiaceae (marga Garcinia), Sapindaceae (marga Nephelium) dan suku Bombacaceae (marga Durio). Empat jenis komoditas buah-buahan dari keempat marga tersebut telah ditetapkan sebagai "buah-buahan unggulan nasional", masing-masing adalah buah mangga, manggis, rambutan dan durian (Winarno, 2000). 
Kebun raya Purwodadi adalah kawasan konservasi ex situ yang memiliki koleksi tanaman buah lokal Indonesia yang berasal dari hasil eksplorasi, pertukaran koleksi dengan kebun raya lain atau merupakan hasil sumbangan. Koleksi tanaman tersebut ditata mengikuti pola taksonomi, bioregion, tematik atau kombinasi pola-pola tersebut untuk kegiatan konservasi, penelitian, pendidikan, wisata dan jasa lingkungan (Peraturan Presiden Nomor 93 tahun 2011). Pendataan dan pemetaan tanaman buah lokal Indonesia di Kebun Raya Purwodadi perlu dilakukan untuk mengetahui keanekaragaman jenisnya serta informasi yang terkumpul diharapkan dapat menjadi dasar pengelolaan dan pengambilan kebijakan terkait pembuatan rute tracking dan taman tematik buah lokal Kebun Raya Purwodadi.

\section{Metodologi}

\subsection{Tempat dan Waktu}

Penelitian dilaksanakan di Kawasan Kebun Raya Purwodadi pada Bulan April-Mei 2019.

\subsection{Bahan dan Peralatan}

Bahan atau objek penelitian adalah tanaman buah lokal Indonesia koleksi Kebun Raya Purwodadi. Peralatan yang digunakan dalam penelitian ini terdiri dari: Peta Kebun Raya Purwodadi, galah untuk mengambil buah, handphone untuk mengambil dokumentasi, alat tulis serta buku katalog untuk identifikasi lokasi dan jenis tanaman di lapangan. Laptop untuk penulisan data hasil pengamatan.

\subsection{Pengumpulan Data}

Jenis tanaman buah lokal Indonesia yang telah ditanam di Kebun Raya Purwodadi didata dengan mengacu pada katalog An Alphabetical List of Plant Species Cultivated in Purwodadi Botanic Garden (2012) melalui observasi langsung di lapangan dengan pencuplikan sampel dilakukan dengan metode jelalah. Informasi keberadaan dan pemanfaatan potensi tanaman buah lokal dilakukan melalui wawancara kepada penyelia dan teknisi lapangan. Penentuan responden dilakukan dengan purposive sampling karena tidak semua staf Kebun Raya Purwodadi mengetahui tentang informasi yang diberikan. Studi literarur juga dilakukan untuk memperkaya informasi pemanfaatan potensi jenis tanaman buah lokal.

\subsection{Analisis Data}

Data yang diperoleh, selanjutnya dianalisis secara deskriktif dan diolah dalam bentuk tabel dan grafik, sehingga dapat diketahui jumlah jenis dan potensi pemanfaatannya.

\section{Hasil dan Pembahasan}

\section{Koleksi Buah Lokal Indonesia di Kebun Raya Purwodadi}

Keanekaragaman jenis dan plasma nutfah buah-buahan asli Indonesia yang cukup besar sangat penting terutama sebagai modal dasar untuk pemuliaan tanaman buah-buahan.Inventarisasi kekayaan jenis buah-buahan asli Indonesia perlu dilakukan agar dapat dimanfaatkan, khususnya dalam usaha meningkatkan kualitas dan kuantitas buah-buahan asli Indonesia sehingga dapat menambah dan meningkatkan usaha penganekaragaman jenis buah-buahan yang dapat dimakan di Indonesia (Uji, 2007). Berdasarkan hasil pengamatan di Kebun Raya Purwodadi, terdapat 96 jenis spesies tanaman buah lokal yang termasuk ke dalam 24 famili (Tabel 1).

Tabel 1. Daftar jenis buah Lokal Indonesia Koleksi Kebun Raya Purwodadi

\begin{tabular}{rlll}
\hline No. & \multicolumn{1}{c}{ Nama Ilmiah } & \multicolumn{1}{c}{ Family } & \multicolumn{1}{c}{ Nama Lokal } \\
\hline 1 & Bouea macrophylla & Anacardiaceae & Buah Gandaria \\
2 & Bouea oppositifolia & Anacardiaceae & Raman \\
3 & Mangifera casturi & Anacardiaceae & Kasturi \\
4 & Mangifera indica & Anacardiaceae & Mangga \\
5 & Mangifera foetida & Anacardiaceae & Pakel \\
6 & Mangifera minor & Anacardiaceae & Fo karuku \\
7 & Mangifera odorata & Anacardiaceae & Kuweni \\
8 & Mangifera similis & Anacardiaceae & Mangga pipit \\
9 & Spondias cytherea & Anacardiaceae & Kedondong \\
10 & Annona squamosa & Annonaceae & Srikaya
\end{tabular}




\begin{tabular}{|c|c|c|c|}
\hline No. & Nama Ilmiah & Family & Nama Lokal \\
\hline 11 & Stelechocarpus burahol & Annonaceae & Kepel/Burahol \\
\hline 12 & Uvaria grandiflora & Annonaceae & Pisang akar \\
\hline 13 & Uvaria littoralis & Annonaceae & Oyod kalak \\
\hline 14 & Borassus flabellifer & Arecaceae & Siwalan \\
\hline 15 & Caryota mitis & Arecaceae & Genduru \\
\hline 16 & Caryota rumphiana & Arecaceae & Nibung \\
\hline 17 & Salacca borneensis & Arecaceae & Salak Kalimantan \\
\hline 18 & Salacca sumatrana & Arecaceae & Salak Sumatra \\
\hline 19 & Salacca Zalacca & Arecaceae & Salak \\
\hline 20 & Averrhoa bilimbi & Averrhoaceae & Blimbing wuluh \\
\hline 21 & Protium javanicum & Burseraceae & Trenggulun \\
\hline 22 & Garcinia celebica & Clusiaceae & Baros \\
\hline 23 & Garcinia dulcis & Clusiaceae & Buah Mundu \\
\hline 24 & Garcinia parvifolia & Clusiaceae & Juri konis \\
\hline 25 & Dilenia celebica & Dilleniaceae & Nyeher \\
\hline 26 & Dillenia indica & Dilleniaceae & Sempur \\
\hline 27 & Dilenia serata & Dilleniaceae & Dongi \\
\hline 28 & Diospyros blancoi & Ebenaceae & Bisbul \\
\hline 29 & Diospyros lolin & Ebenaceae & Lorin \\
\hline 30 & Diospyros malabarica & Ebenaceae & Culiket \\
\hline 31 & Elaeocarpaceae angustifolius & Elaeocarpus & Ganitu \\
\hline 32 & Antidesma bunius & Euphorbiaceae & Buah Buni \\
\hline 33 & Antidesma minus & Euphorbiaceae & Buni Borneo \\
\hline 34 & Antidesma montanum & Euphorbiaceae & - \\
\hline 35 & Antidesma pentandrum & Euphorbiaceae & Uni manis \\
\hline 36 & Baccaurea dulcis & Euphorbiaceae & Cupa \\
\hline 37 & Baccaurea montleyana & Euphorbiaceae & Rambai \\
\hline 38 & Baccaurea polyneura & Euphorbiaceae & - \\
\hline 39 & Blumeodendron tokbrai & Euphorbiaceae & Keterung \\
\hline 40 & Emblica officinalis & Euphorbiaceae & Kemloko \\
\hline 41 & Cynometra cauliflora & Fabaceae & Namnam \\
\hline 42 & Dialium platysepalum & Fabaceae & Keranji kuning \\
\hline 43 & Inocarpus fagiferus & Fabaceae & Gayam \\
\hline 44 & Tamarindus indica & Fabaceae & Asem \\
\hline 45 & Salacia chinensis & Hippocrateaceae & Akar pelanduk \\
\hline 46 & Melastoma malabatricum & Melastomaceae & Senduduk \\
\hline 47 & Lansium domesticum & Meliaceae & Kokosan \\
\hline 48 & Sandoricum koetjape & Meliaceae & Buah Kecapi \\
\hline 49 & Artocarpus anisophyllus & Moraceae & Bakil/Pupuan \\
\hline 50 & Artocarpus elasticus & Moraceae & Benda \\
\hline 51 & Artocarpus gomezianus & Moraceae & Penangkaan \\
\hline 52 & Artocarpus integer & Moraceae & Buah Cempedek \\
\hline 53 & Artocarpus odoratissimus & Moraceae & Terap \\
\hline 54 & Artocarpus rigidus & Moraceae & - \\
\hline 55 & Artocarpus sericicarpus & Moraceae & - \\
\hline 56 & Artocarpus tamaran & Moraceae & - \\
\hline 57 & Artocarpus tesymanii & Moraceae & - \\
\hline 58 & Ficus drupaceae & Moraceae & Bulu timun \\
\hline 59 & Ficus montana & Moraceae & Uyah-uyahan \\
\hline 60 & Ficus racemosa & Moraceae & Lo \\
\hline 61 & Streblus asper & Moraceae & Pelih/Serut \\
\hline
\end{tabular}




\begin{tabular}{|c|c|c|c|}
\hline No. & Nama Ilmiah & Family & Nama Lokal \\
\hline 62 & Streblus ilicifolia & Moraceae & Kosa-kosa \\
\hline 63 & Musa acuminata & Musaceae & Pisang klutuk \\
\hline 64 & Eugenia uniflora & Myrtaceae & Buah Dewandaru \\
\hline 65 & Psidium guajava & Myrtaceae & Jambu kluthuk \\
\hline 66 & Syzygium cumini & Myrtaceae & - \\
\hline 67 & Syzygium javanicum & Myrtaceae & Jambu jawa \\
\hline 68 & Syzygium malaccense & Myrtaceae & - \\
\hline 69 & Syzygium nervosum & Myrtaceae & Jambon \\
\hline 70 & Syzygium polyanthum & Myrtaceae & Salam \\
\hline 71 & Syzygium polycephalum & Myrtaceae & Gowok, dompyong \\
\hline 72 & Baccaurea motleyana & Phyllanthaceae & Rambai \\
\hline 73 & Baccaurea racemosa & Phyllanthaceae & - \\
\hline 74 & Glochidion obscurum & Phyllanthaceae & Uris-urian \\
\hline 75 & Phyllanthus acidus & Phyllanthaceae & Cermai \\
\hline 76 & Ziziphus rotundifolia & Rhamnaceae & Bukol \\
\hline 77 & Aegle marmelos & Rutaceae & Maja/Mojolegi \\
\hline 78 & Citrus aurantifolia & Rutaceae & Jeruk pecel \\
\hline 79 & Citrus hystrix & Rutaceae & Jeruk purut \\
\hline 80 & Citrus maxima & Rutaceae & Jeruk macan \\
\hline 81 & Limonia acidissima & Rutaceae & Kawista \\
\hline 82 & Flacourtia inermis & Salicaceae & Buah Lobi-lobi \\
\hline 83 & Flacourta rukam & Salicaceae & Rukam/Rukem \\
\hline 84 & Dimocarpus longan & Sapindaceae & Medaru \\
\hline 85 & Lepisanthes amoena & Sapindaceae & Buah Sobo \\
\hline 86 & Lepisanthes rubiginosa & Sapindaceae & Katilayu \\
\hline 87 & Mischocarpus pentapetalus & Sapindaceae & - \\
\hline 88 & Nephelium cuspidatum & Sapindaceae & - \\
\hline 89 & Nephelium lappaceum & Sapindaceae & Rambutan \\
\hline 90 & Pometia pinnata & Sapindaceae & Buah Matoa \\
\hline 91 & Schleichera oleosa & Sapindaceae & - \\
\hline 92 & Xerospermum noronhianum & Sapindaceae & Rambutan pacet \\
\hline 93 & Chrysophyllum cainoto & Sapotaceae & Buah Genitu \\
\hline 94 & Manikara kauki & Sapotaceae & Sawo Kecik \\
\hline 95 & Pavena acuminata & Sapotaceae & Jengkol balam \\
\hline 96 & Phaleria capitata & Thymelaeceae & 0 \\
\hline
\end{tabular}

Dari tabel 1 dapat dilaporkan bahwa ada beberapa suku yang jumlah jenisnya cukup besar, antara lain suku Moraceae (14 jenis), Anacardiaceae (9 jenis) dan Euphorbiaceae (28 jenis). Ketiga suku yang mempunyai keanekaragaman jenis buah-buahannya yang tinggi ini berpotensi untuk diteliti dan dikembangkan, karena keanekaragaman jenis yang tinggi merupakan modal utama dalam melakukan usaha pemuliaan tanaman. Berikut ini diuraikan beberapa spesies buah lokal Indonesia koleksi Kebun Raya Purwodadi yang bernilai ekonomi dan berpotensi untuk dikembangkan.

Manggis dan kerabatnya (Garcinia spp.)

Salah satu spesies dari genus Garcinia adalah mundu (Garcinia dulcis) dengan buah berwarna hijau muda saat masih mentah dan berubah menjadi kuning cerah (mengkilat) ketika masak (Gambar 1). 

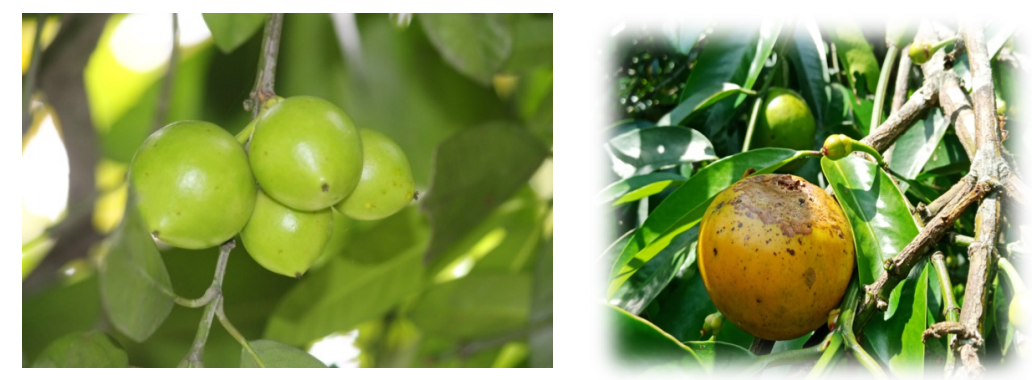

Gambar 1. Garcinia dulcis

Mundu memeliki beberapa kelebihan diantaranya mulai dari kulit batangnya yang berguna sebagai pewarna pada anyam-anyaman dan getah buah untuk pewarna kuning jika dicampur temulawak dan tawas. Selain itu, buah yang matang dapat dimakan dan dibuat selai, sedangkan bijinya jika dilumatkan dengan cuka dan garam dapat digunakan sebagai obat pada bengkak-bengkak kelenjar (Thong, 2017).

\section{Burahol}

Burahol merupakan jenis tanaman buah-buahan Indonesia, dengan nama lain kepel, simpel, dan kecindul (Jawa). Buah berbentuk bulat, berwarna kecoklatan, diameter 5-6 cm, berbijiempat atau lebih dan berbentuk elip (Gambar 2). Selain menghasilkan buah segar burahol juga digunakan sebagai parfum, obat tradisional (mengurangibau badan), dan bahan kontrasepsi. Kayu burahol digunakan untuk perkakas rumah tangga dan bahan bangunan. Burahol ini juga biasa ditanam sebagai tanaman hias. Musim berbunga adalah September-Oktober dan berbuah pada MaretApril, serta perbanyakan dengan biji. Burahol merupakan jenis tanaman penghasil wangi-wangian, hal ini telah banyak dimanfaatkan sejak dahulu. Buahnya dimakan untuk melancarkan air seni, menghilangkan bau nafas, bau keringat, dan membantu mencegah peradangan ginjal.

Buah burahol mengandung alkoloid yang dapat digunakan untuk mencegah kehamilan. Oleh sebab itu, dahulu buah burahol kerapkali dikonsumsi oleh para wanita bangsawan, khususnya putri keraton, baik untuk pewangi air seni dan keringat maupun untuk mencegah kehamilan (Heyne 1987).
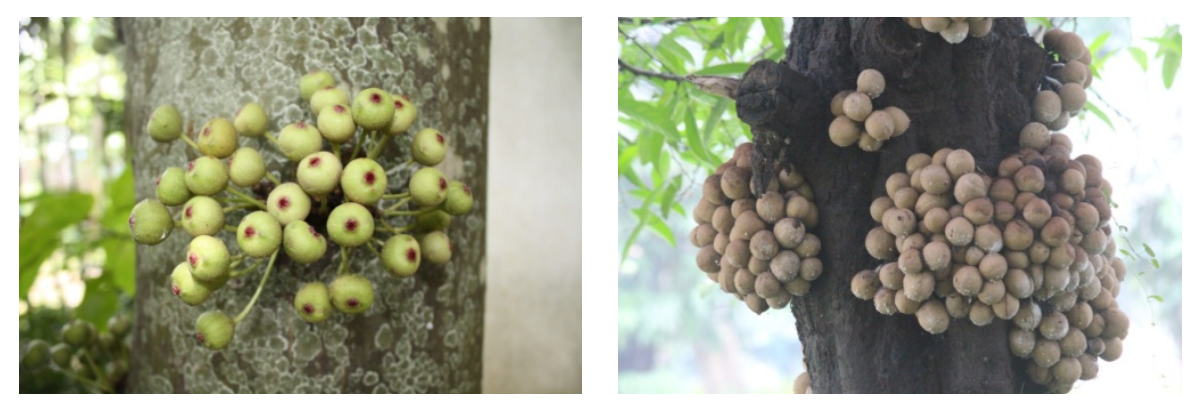

Gambar 2. Stelechocarpus burahol 


\section{Kesimpulan}

Berdasarkan hasil penelitian yang telah dilakukan dapat disimpulkan bahwa terdapat 96 spesies tanaman buah lokal Indonesia koleksi Kebun Raya Purwodadi. Suku yang jumlah jenisnya cukup besar, antara lain suku Moraceae (14 jenis), Anacardiaceae (9 jenis) dan Euphorbiaceae (28 jenis).

\section{Referensi}

Dodo. 2015. Keanekaragaman dan Konservasi Tumbuhan Langka Indonesia. Warta Kebun Raya. 13(2):37-42

Heyne, K. 1987. Tumbuhan berguna Indonesia. Jilid II. Jakarta: Badan Litbang Kehutanan.

Kebun Raya Purwodadi. 2012. An Alphabetical List of Plant Species Cultivated in Purwodadi Botanic Garden. Purwodadi-LIPI

Prosea, 1991. Edible Fruits and Nuts. Bogor. Plant Resources of South-East Asia.

Sunarto, A.T. 1992. Stelechocarpusburahol (Blume) Hook.f.\& Thomson. In.Verheij, E.W.M. and R.E. Coronel (eds).Plant Resources of South-East Asia No.2. Edible Fruits and Nuts. Prosea FondationBogor, Indonesia. Pp 290-291.

Thong, N . 2017.Diuretic and Hypotensive Effect of Morelloflavone from Garcinia dulcis. Sains Malaysiana. 46(9): 1479-1490

Uji, T. 2007. Review. Keanekaragaman Jenis Buah-Buahan Asli Indonesia dan Potensinya. Biodiversitas 8(2):157-167.

Widyatmoko, D. dan Irawati. 2007. Kamus Istilah Konservasi. Pusat Konservasi Tumbuhan Kebun Raya Bogor. Lembaga Ilmu Pengetahuan Indonesia.

Winarno, 2000. Kebijakan pemerintah dalam pengembangan hortikultura Indonesia. Prosiding Seminar Sehari. Hari Cinta Puspa dan Satwa Nasional. Menggali potensi dan meningkatkan prospek tanaman hortikultura menuju ketahanan pangan. Pusat Konservasi Tumbuhan. Kebun Raya Bogor : 9-15. 